\title{
Sirenomelia: two cases in Cali, Colombia
}

\author{
Wilmar Saldarriaga, ${ }^{1}$ Maria Jimena Salcedo-Arellano, ${ }^{2}$ Julian Ramirez-Cheyne ${ }^{1}$
}

'Department of Morphology, Universidad del Valle, Cali, Valle del Cauca, Colombia ${ }^{2}$ Department of Medicine and Surgery, Universidad del Valle, Cali, Valle del Cauca, Colombia

\section{Correspondence to}

Dr Wilmar Saldarriaga-Gil, wilmar.saldarriaga@ correounivalle.edu.co

Accepted 13 January 2015
CrossMark

To cite: Saldarriaga W, Salcedo-Arellano MJ,

Ramirez-Cheyne J. BMJ Case Rep Published online: [please include Day Month Year] doi:10.1136/bcr-2014207543

\section{SUMMARY}

We report two cases of sirenomelia, a rare congenital defect with a prevalence rate of 1:100 000 births; both cases were observed in Cali, Colombia. Both pregnant women were referred from Buenaventura, Colombia. The expecting mothers shared multiple adverse sociodemographic factors. Their homes were located in a city where the entire population is of low socioeconomic status living under conditions of extreme poverty. They were uneducated, with nutritional deficiencies and no access to drinking water most of the time. Both were exposed to water and fish from a nearby river contaminated with leachate from a poorly managed landfill. A similar relation was previously reported in Cali in 2005 between environmental factors and sirenomelia. We suggest that there is a common aetiological factor of environmental origin between these two sirenomelia cases and propose that exposure to derivatives from landfills should be included among the factors for this rare defect of multifactorial aetiological origin.

\section{CASE PRESENTATION \\ First case}

A 33-year-old primigravida woman from Buenaventura, at 28 weeks gestation, according to her last menstrual period, with estimated conception date 12/20/2011, was living under low social class conditions without access to clean drinking water. She frequently used water from the nearby river for personal hygiene and daily requirements. She had an incomplete elementary level of education and held government subsidised health insurance. She had been referred to Cali, Colombia, due to findings of an ultrasound reporting high-resistance flow of the left uterine artery, intrauterine growth restriction (IUGR) and oligohydramnios; she also presented severe preeclampsia. She had four antenatal follow-up appointments during her pregnancy. An O'Sullivan test reported normal glycaemic levels; none of the other prenatal screening tests revealed any anomalies. An ultrasound performed on admission to the institution in Cali reported anhydramnios, pulmonary hypoplasia, IUGR and a single umbilical artery (SUA); findings suggested a possible diagnosis of sirenomelia. The patient was rushed into the operating room and a caesarean section was performed. The premature newborn weighed $930 \mathrm{~g}$ (percentile 3-10), had an Apgar score of 5/10 at the first minute and 0/10 at $5 \mathrm{~min}$, presented dolichocephaly, absence of external genitalia and anus, fused lower limbs and fused feet (figure 1) with oligodactyly (two toes on each foot) (figure 2). In addition to the morphotype abnormalities, the autopsy described renal hypoplasia, atrophic bladder and urethra, blind bowel and ovarian tissue. The X-ray showed sacral agenesia, paired femora and tibiae and a single fused fibula, classified as type II sirenomelia according to Stocker and Heifetz classification (figure 3$)^{1}$

\section{Second case}

A 32-year-old woman, on her second pregnancy, at 37 weeks gestation according to her last menstrual period and with estimated conception date 10/22/ 2011 living under low social class conditions without access to clean drinking water. She frequently used water from the nearby river for personal hygiene and daily habits. She also had an incomplete elementary level of education and held government subsidised health insurance. She had been referred from Buenaventura to Cali, Colombia, for further fetal evaluation. She started antenatal control at 14 weeks and continued it for 6 weeks; neither the glucose curve nor any of the prenatal screening tests carried out showed alterations. Her medical history revealed an episode of fever and vesicular skin rash lasting at least 5 days during the first trimester of the current pregnancy. Additionally, she had four ultrasounds reporting IUGR. On arrival at Cali, an ultrasound confirmed IUGR, and oligohydramnios and a caesarean section were performed. The newborn weighed $1970 \mathrm{~g}$ (less than percentile 1), with Apgar score of $7 / 10$ at the first minute, $3 / 10$ at $5 \mathrm{~min}$ and $0 / 10$ at $10 \mathrm{~min}$. The infant presented Potter's face, a SUA, absence of genitalia and anus, fused lower limbs (figure 4), fused feet in extreme dorsiflexion, with oligodactyly eight toes, with lateral location of the hallux. The baby had monopus according to Forster (figure 5). ${ }^{2} \mathrm{X}$-ray showed vertebral dysgenaesia (L4-L5), sacral agenesia, fused femora in their proximal two-thirds and a single fibula. The case was classified as type IV sirenomelia according to Stocker and Heifetz (figure 6). ${ }^{1}$ Shortly after birth $3 \mathrm{cc}$ of blood was taken from the umbilical

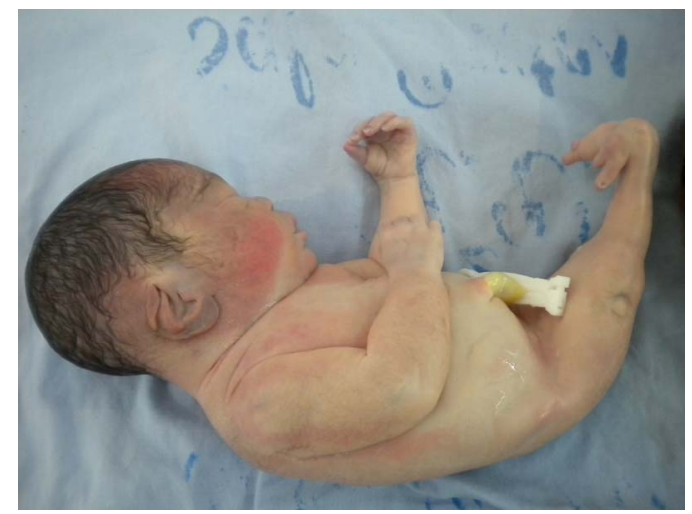

Figure 1 Case 1, newborn with sirenomelia. Note dolichocephaly, absence of genitalia and a single midline limb. 


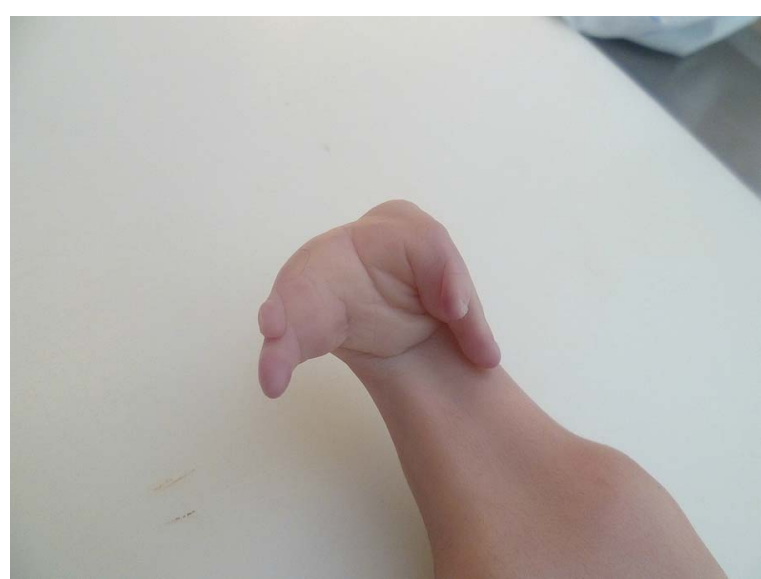

Figure 2 Case 1, distal end of lower limbs of newborn with sirenomelia dipus according to Forster classification. Notice oligodactyly two toes each foot.

cord but cellular growth was not achieved in the lymphocyte culture, therefore it was not possible to carry out the karyotype. The newborn's parents did not give consent to perform an autopsy.

\section{GLOBAL HEALTH PROBLEM LIST}

- Sirenomelia is a rare congenital defect for which the physiopathology and aetiology have not been conclusively determined.

- Economic poverty and adverse sociodemographic conditions have been associated with congenital anomalies.

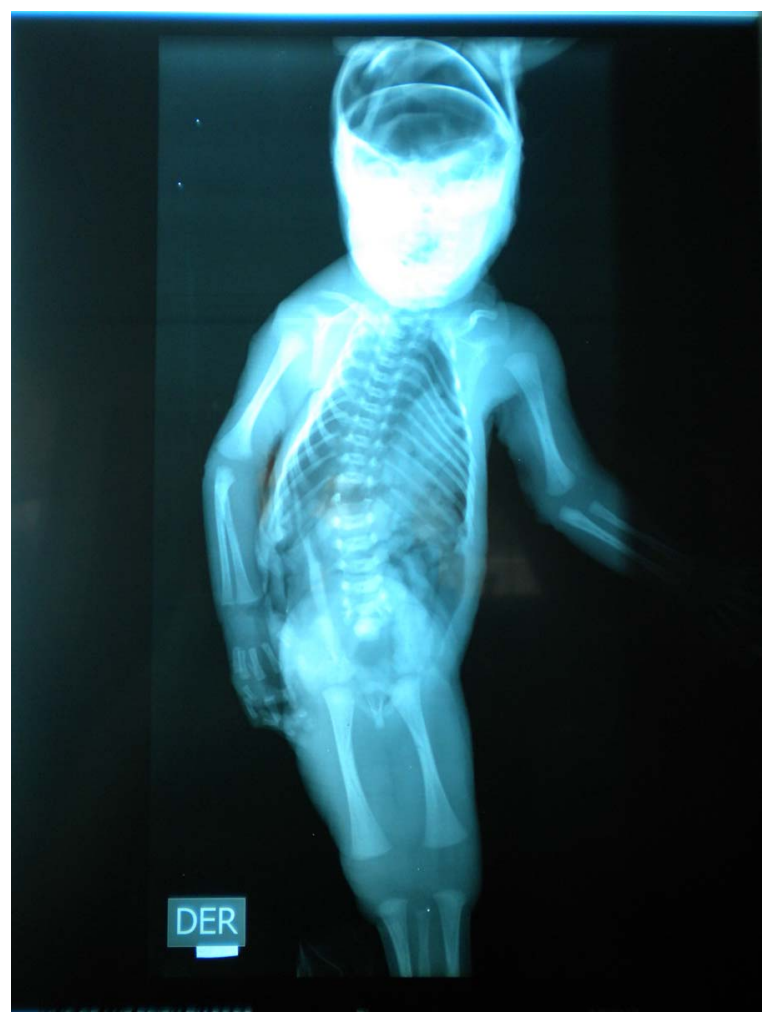

Figure 3 Case 1, X-ray of newborn with sirenomelia type IIaccording to Stocker and Heifetz classification. Note paired femora and tibiae and a single fibula.

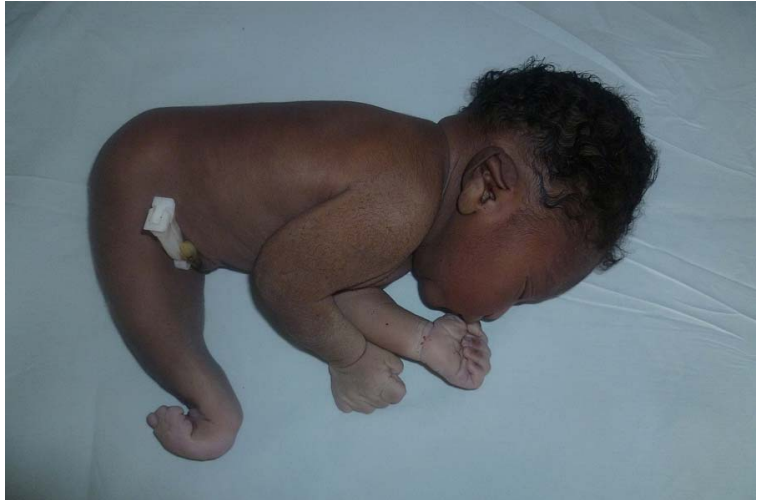

Figure 4 Case 2, newborn with sirenomelia. Note low-set ears, absence of genitalia, fused lower limbs at midline and fused feet in extreme dorsiflexion.

- Sirenomelia cases have been reported from mothers who have been exposed to polluted water due to the inappropriate disposal of trash from mishandled landfills.

\section{GLOBAL HEALTH PROBLEM ANALYSIS}

The global prevalence of sirenomelia is 0.98 in 100000 births, as reported by The International Clearinghouse for Birth Defects Surveillance and Research. The data were gathered from 19 birth defect surveillance system members, who identified 249 cases with sirenomelia out of 25290172 reported births. ${ }^{3}$

Among the possible factors associated with increased risk of sirenomelia, maternal diabetes is the only maternal disease found. ${ }^{4}$ In the cases being reported, the mothers did not present any alterations in the glycaemic tests performed during the antenatal control, eliminating diabetes as the aetiologic agent. Furthermore, exposure to teratogens, such as retinoic acid, cadmium, cyclophosphamide, cocaine and the antiepileptic drug lamotrigine, has been previously reported in association with sirenomelia. ${ }^{3}$ The patients in this report did not ingest any of these agents. On the other hand, risk decreases with advancing maternal age $\mathrm{a}^{5}$; the gestating mothers were in their early $30 \mathrm{~s}$, therefore the cases were presented within a non-increased prevalence age group $(0.87 / 100.000$ births, $95 \%$ CI 0.63 to 1.17$)$ for sirenomelia.

The sirenomelia findings might be explained by two main hypotheses that can account for the abnormal development of

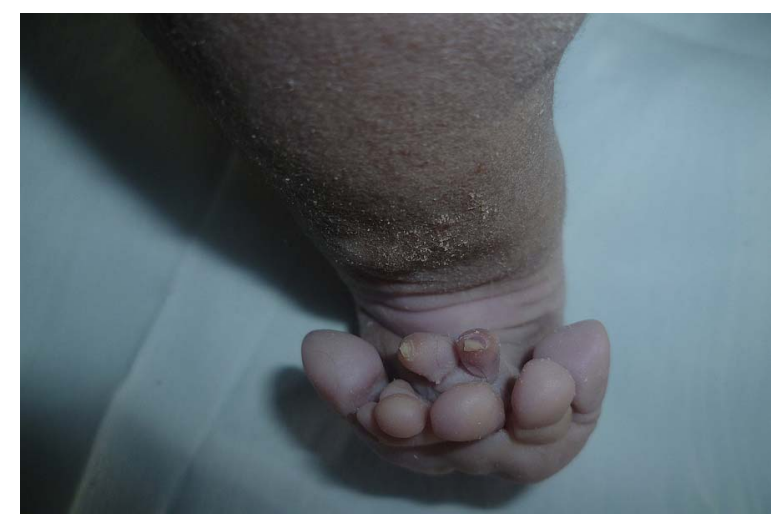

Figure 5 Case 2, distal end of lower limbs of newborn with sirenomelia monopus according to Forster. Notice fused feet in extreme dorsiflexion, eight toes and lateral position of hallux. 


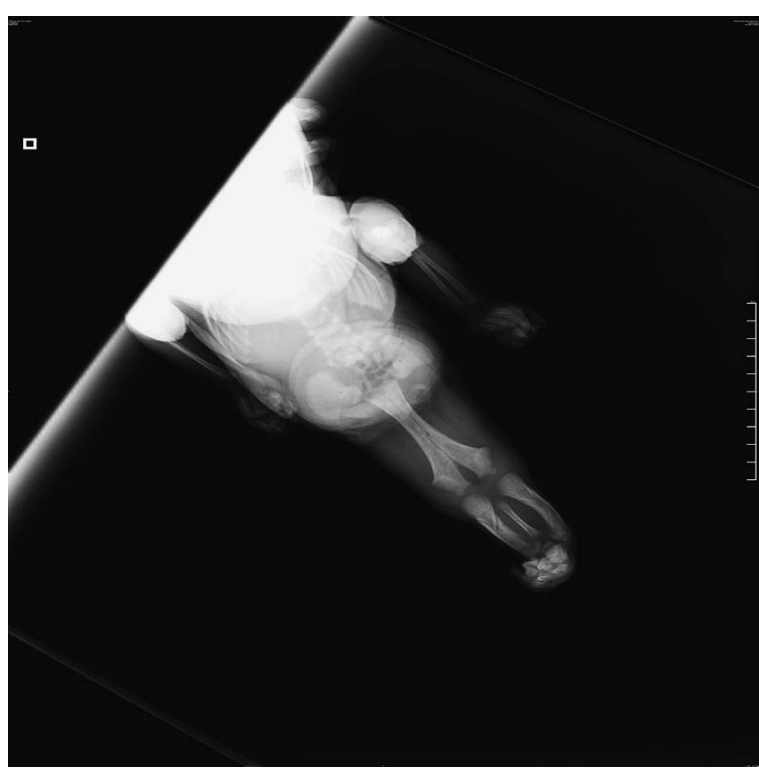

Figure 6 Case 2, X-ray of newborn with sirenomelia. Type IV according to Stocker and Heifetz classification. Note femora partly fused and a single fibula.

the embryo. These hypotheses are: the vascular steal hypothesis and the defective blastogenesis hypothesis. ${ }^{3}$ The vascular steal hypothesis suggests the existence of an anomalous vessel impeding proper blood flow to the caudal end of the embryo. ${ }^{67}$ One of the most important early findings in prenatal imaging is a SUA of abnormal origin, with SUA of vitelline origin being considered characteristic of sirenomelia. ${ }^{8}$ SUA is the most common abnormality of the umbilical cord and largely associated with cardiac and urogenital malformations. ${ }^{9}$ Also associated with SUA is an unusual narrowing of the aorta and privation of several of the branches that normally provide sufficient blood supply to the kidneys and genitalia and the caudal part of the fetus in general. ${ }^{10}$ Both of the reported cases presented a SUA, suggesting that a vascular event necessarily took place in both embryos.

Table 1 Sirenomelia classification

\begin{tabular}{|c|c|c|}
\hline Classification system & Limbs & Feet \\
\hline \multicolumn{3}{|l|}{ (A) Stocker and Heifetz ${ }^{1}$} \\
\hline Type I & $\begin{array}{l}\text { Paired femora, tibiae } \\
\text { and fibulae }\end{array}$ & \\
\hline Type II & Single fibula & \\
\hline Type III & Absent fibulae & \\
\hline Type IV & $\begin{array}{l}\text { Femora partly fused, } \\
\text { single fibula }\end{array}$ & \\
\hline Type V & $\begin{array}{l}\text { Femora partly fused, } \\
\text { absent fibulae }\end{array}$ & \\
\hline Type VI & Single femur and tibia & \\
\hline Type VII & $\begin{array}{l}\text { Single femur, absent } \\
\text { tibiae }\end{array}$ & \\
\hline \multicolumn{3}{|l|}{ (B) Förster ${ }^{2}$} \\
\hline Apodal symmelia (apus) & $\begin{array}{l}\text { Fused, one femur and } \\
\text { one tibia }\end{array}$ & None \\
\hline $\begin{array}{l}\text { Monopodal symmelia } \\
\text { (monopus) }\end{array}$ & $\begin{array}{l}\text { Partially fused, two } \\
\text { femora or two tibiae }\end{array}$ & $\begin{array}{l}\text { One foot or severe } \\
\text { fusion of both feet }\end{array}$ \\
\hline Dipodal symmelia (dipus) & $\begin{array}{l}\text { Non-fused femora and } \\
\text { tibiae }\end{array}$ & Two feet \\
\hline
\end{tabular}

The defective blastogenesis hypothesis suggests a primary anomaly in the mesoderm that the caudal end of the embryo will derive from. ${ }^{11}$ This will produce renal, sacral, genitourinary and lower limb abnormalities. ${ }^{11}$ Sirenomelia sequence was classified by Forster in 1865 based on the absence or presence of feet. In 1987, Stocker and Heifetz grouped the syndrome into seven types of semicontinuous progressive levels of severity based on the presence of skeletal structures of thighs and legs (table 1). Our first case presented two femora, tibiae and single fibula (figure 3) and partially fused feet (figure 2), it was classified as type II according to Stocker and Heifetz and dipus according to Forster. The second case presented fused femora in their proximal two-thirds, tibiae, single fibula (figure 6) and severely fused feet (figure 5), it was classified as type IV according to Stocker and Heifetz and monopus according to Forster.

The relationship between adverse social determinants and risk for congenital anomalies has been described previously in the world and in Latin America specifically. The living conditions of the mother at the time of conception, such as her health status, nutritional condition, educational and socioeconomic level, age, number of previous children, number of prenatal visits and type of insurance, among other factors, can critically influence the perinatal outcome. These factors may precipitate a specific exposure such as diabetes or drug use in the periconceptional period and affect the development of the embryo in the period of organogenesis. ${ }^{12} 13$ Both mothers in the cases reported lived in a city where the entire population is of low socioeconomic status living under conditions of extreme poverty. They were uneducated, with nutritional deficiencies, and did not have basic facilities such as access to drinking water.

In 2008, ECLAMC reported a non-random, time-space cluster of four sirenomelia cases in the city of Cali, Colombia, within a 55 day period, born at a single maternity hospital in 2004-2005, after the expecting mothers' were exposed to a polluting active landfill along the Cauca River, the most probable aetiological common factor. ${ }^{14-16}$ Both the cases of sirenomelia being reported were engendered within a period of 8 weeks during the last trimester of 2011, with a distance between their homes no greater than $2 \mathrm{~km}$ in Buenaventura; this city is located on the west coast of Colombia, $122 \mathrm{~km}$ from Cali (where the prior cluster was reported during 20042005). The expecting mothers did not have any exposure to the active landfill along the Cauca River located in Cali. However, the city of Buenaventura also has a landfill that, similarly to the reported landfill of Cali, does not have appropriate structural conditions and of which the management is poor. The leachate from the landfill drains to a stream that is less than $300 \mathrm{~m}$ away from it, rendering changes in the ecosystem, particularly in fish. This stream drains to the Dagua River, which is the main water source of the region and of the city of Buenaventura.

What these cases have in common with the former cases are the geographical proximity of the patients (they did not change residences during the periconceptional period). During their normal daily activities they were exposed to the river that flows near their homes, where they would wash their clothes and perform personal hygiene activities. Other considerable factors are their low social and economic conditions with consequent nutritional deficiencies due to a non-balanced diet and the consumption of fish from the Dagua River. Being a very rare congenital defect it is unlikely that there is no existing relation between these two cases. In these women we postulate that the sum of nutritional deficiencies and exposure to leachate from the landfill in the nearby river by the consumption of fish and/ 
or direct contact with the water had an aetiological relationship with the fetuses with sirenomelia.

\section{Learning points}

- The two reported cases shared geographical proximity of patients, close-dated estimated conception dates, low social and economic conditions with nutritional deficits and exposure to a contaminated river by an inadequately managed landfill.

- Two cases of sirenomelia are described, the first type II and dipus, and the second type IV and monopus, according to the classification of Stocker and Heifetz, 1987, and Forster, 1865.

- We propose that as sirenomelia is a rare defect of multifactorial aetiology, exposure to landfill derivatives should be included among the aetiological factors.

Acknowledgements The authors wish to thank the mothers of the cases, the doctors who were involved in the medical attention of the patients and, especially, the pathologists for their contribution to this publication.

\section{Competing interests None.}

Patient consent Obtained.

Provenance and peer review Not commissioned; externally peer reviewed.

\section{REFERENCES}

1 Stockers JT, Heifetz SA. Sirenomelia. A morphological study of 33 cases and review of the literature. Perspect Pediatr Pathol 1987;10:7-50.
2 Förster A. Die Missbildungen des Menschen. Jena, G.D.R: Atlas, Friedrich, 1865.

3 Orioli IM, Amar E, Arteaga-Vazquez J, et al. Sirenomelia: an epidemiologic study in a large dataset from the international clearinghouse of birth defects surveillance and research, and literature review. Am J Med Genet C Semin Med Genet 2011157C:358-73.

4 Valenzano M, Paoletti R, Rossi A, et al. Sirenomelia, pathological features, antenatal ultrasonographic clues and a review of current embryogenic theories. Hum Reprod Update 1999;5:82-6.

5 Castilla EE, Mastroiacovo P. Very rare defects: what can we learn? Am J Med Genet Part C Semin Med Genet 2011;157:252-61.

6 Hentschel J, Stierkorb E, Schneider G, et al. Caudal regression sequence. Vascular origin? J Perinatol 2006;26:445-7.

7 Pillay M, Yesodharan D, Narayanan DL, et al. Sirenomelia: case reports and current concepts of pathogenesis. Pediatr Dev Pathol 2012;15:403-6.

8 Stevenson RE, Jones KL, Phelan MC, et al. Vascular steal: the pathogenetic mechanism producing sireno- melia and associated defects of the viscera and soft tissues. Pediatrics 1986;78:451-7.

9 Vasanthalakshmi GN, Pushpalatha, Mehta P, et al. Single umbilical artery and pregnancy outcome: cause for concern. I South Asian Feder Obst Gynae 2012:4:103-5.

10 Martınez-Frias ML, Bermejo E, Rodriguez- Pinilla E, et al; ECEMC Working Group. Does single umbilical artery (SUA) predict any type of congenital defect? Clinicalepidemiological analysis of a large consecutive series of malformed infants. Am J Med Genet Part A 2008;146A:15-25.

11 Garrido-Allepuz C, Haro E, González-Lamuño D, et al. A clinical and experimental overview of sirenomelia: insight into the mechanisms of congenital limb malformations. Dis Model Mech 2011:4:289-99.

12 Kucik JE, Cassell $\mathrm{CH}$, Alverson CJ, et al. Role of health insurance on the survival of infants with congenital heart defects. Public Health 2014;104:e62-70.

13 Dean SV, Lassi ZS, Imam AM, et al. Preconception care: nutritional risks and interventions. Reprod Health 2014;11(Suppl 3):S3.

14 Castilla EE, Mastroiacovo P, Lopez-Camelo J, et al. Sirenomelia and cyclopia cluster in Cali, Colombia. Am J Med Genet A 2008;146A:2626-36.

15 Orioli IM, Mastroiacovo P, Lopez-Camelo J, et al. Clusters of sirenomelia in South America. Birth Defects Res A Clin Mol Teratol 2009;85:112-18.

16 Saldarriaga W, Isaza $C$, Castilla EE. Eight year follow-up of an epidemic of sirenomelia in Cali, Colombia. Am J Med Genet A 2014;164A:2403.

Copyright 2015 BMJ Publishing Group. All rights reserved. For permission to reuse any of this content visit

http://group.bmj.com/group/rights-licensing/permissions.

BMJ Case Report Fellows may re-use this article for personal use and teaching without any further permission.

Become a Fellow of BMJ Case Reports today and you can:

- Submit as many cases as you like

- Enjoy fast sympathetic peer review and rapid publication of accepted articles

- Access all the published articles

- Re-use any of the published material for personal use and teaching without further permission

For information on Institutional Fellowships contact consortiasales@bmjgroup.com

Visit casereports.bmj.com for more articles like this and to become a Fellow 